LI Jianbiao, REN Guangqian, MA Qiuhua, LIU Lüke

\title{
An experimental study on investors' status quo bias and its determinants
}

(C) Higher Education Press and Springer-Verlag 2009

\begin{abstract}
Status quo bias is an important factor which affects investors' decision-making. The extant research on this issue only takes the prospect theory into consideration. In fact, framing effect, investor emotion and information structure are also important variables affecting status quo bias. This paper explores the impact on investors' status quo bias from the perspectives of framing effect, investor emotion and information structure, using the experimental method. Results show that investors' status quo bias is higher in the price differential frame than in the ratio frame of the investable portfolio. In addition, investors' status quo bias does exist in the three emotions conditions. Particularly, status quo bias is lower in the positive emotion investors and higher in the negative emotion. Respondents' choice of certain options is five times as uncertain options. The level of status quo bias in self-status assignment group is higher than that in external-status assignment group.
\end{abstract}

Received February 15, 2009

LI Jianbiao ( $\triangle)$

Research Center of Corporate Governance, School of Business, Nankai University, Tianjin 300071, China

E-mail: biaoj1@126.com

REN Guangqian

Research Center of Corporate Governance, School of Business, Nankai University, Tianjin 300071, China

E-mail:rgq1982@163.com

MA Qiuhua

Department of Economics, University of New Mexico, Albuquerque NM 87131, U.S.

E-mail: qiuhuanihao@163.com

LIU Lüke

Research Center of Corporate Governance, School of Business, Nankai University, Tianjin 300071, China

E-mail:1vke@mail.nankai.edu.cn 
Keywords status quo bias, framing effect, investor emotion, information structure

摘要 现状偏见是影响投资者决策的一个重要因素, 现有研究主要利用前景理论对其 进行阐释。框架效应、投资者情绪以及信息结构在投资者现状偏见中起着重要作用。 利用实验方法研究了三者对投资者现状偏见的影响, 研究结果表明: 差值投资组合框 架中投资者被试的现状偏见程度高于比率投资组合框架中的投资者被试的现状偏见 程度; 三种情绪组中均存在投资者现状偏见, 积极情绪下被试的偏见水平较低, 消极 情绪下被试的偏见水平较高; 被试选择信息结构确定的选项是选择信息模糊选项的 5 倍, 投资者被试对外在现状赋值的现状偏见小于自我现状赋值的现状偏见程度。

关键词 现状偏见，框架效应，投资者情绪，信息结构

\section{Introduction}

It is essential to improve the diathesis of investors in the mature stock market. To this end, reducing the status quo bias level of investors is an important aspect among other measures. Therefore, how and from which perspectives to reduce the status quo bias level of investors are of great theoretical and practical importance.

The extant research is largely built upon the prospect theory and the regret evading theory. The prospect theory has an important position in the field of behavioral finance, despite its weaknesses. For example, when measuring the utility of people, researchers assume that the former utility in the past is the benchmark. People only care about the profit and loss, rarely concern about the uncertainty of the future and the effect of emotion and information on the behavioral decisions of respondents. The regret evading and other theories analyze the status quo bias of investors from different perspectives and find out the reasons behind the status quo bias of investors, yet they are also one-sided.

The existing research rarely considers the influence of framing effect, investor emotion and information structure on investors' status quo bias. However, these three factors play important roles in theoretical analysis and practical application of status quo bias. Framing effect is one of the important factors which impact the decision-making of investors. Studies have confirmed the existence of framing effect and its impact on the decision-making of investors. On the other hand, investor emotion has been one of the research emphases in behavioral economics. Different emotion can result in different decision-making behavior and different level of status quo bias of the investors. As one of the necessary conditions for making decisions, information exerts much influence on decision-making of respondents. Under different information structures, the level of status quo bias is different. 
Based on the above discussion, we probe into investors' status quo bias from perspectives of framing effect, emotion and information structure as well as influence of these three factors on investors' status quo bias. We hope that our results can provide decision-making basis for investors and policy makers.

In the following sections, we first introduce the literature review and propose the research hypotheses of this paper from the aspects of framing effect, investor emotion and information structure. Next, we describe the experimental design and the experimental process of the investors' status quo bias. Then, we present the experimental results, and the final section concludes this paper with discussion.

\section{Literature review}

Bias is a prior or pre-judgment. Bourne (1993) believed that bias is the portfolio of feelings, attitudes and behavioral tendencies and a preconceived view. In the areas of psychology and sociology, the studies focused on the essence, the structure and the elimination of bias. In the areas of economics and management, researchers usually investigate bias influence on decision-making behavior, the source of bias and the exhibition of bias. Status quo bias of investors is a typical bias problem in the areas of economics and management. Samuelson and Zeckhauser (1988) defined status quo bias as a tendency to maintain the existing choices when making decision or choices. Status quo bias is an important factor which affects the decision-making of investors. Research on status quo bias of investors can help us grasp the investment rule of investors and improve the effectiveness of decision-making of the relevant departments. It mainly derives from the obtaining phase, the editing phase and the evaluation phase of information in the investment decision-making process. The extant studies mostly focus on the evaluation phase from perspectives of the prospect theory, the regret evading theory and etc.

At present, the prospect theory is the most widely accepted theory in explaining status quo bias (Kahneman and Tversky, 1979). According to this theory, status quo bias is due to investors' loss aversion, in other words, shape of investors' value function looks like S. ${ }^{1}$ In decision making process, people endow more weight

\footnotetext{
${ }^{1}$ Loss and gain have different value functions. The value function of loss is convex and relatively steep; and the value function of gain is concave and relatively flat. This shows that individual feeling on loss is stronger than the contour gain. Kahneman found that the ratio of utility brought by loss to by the same amount of gain is about $2: 1$, which demonstrates that people have unequal judgments about loss and gain in the decision making process. They think more about how to avoid loss and less about how to gain. Due to the fear to lose, people always ask too high prices selling their goods. For the same reason in the stock market, investors tend to become risk-seeking when stock prices fell.
} 
with loss than gain significantly. Morevoer, loss has a greater impact on people's feeling than the same amount of gain. Tversky and Kahneman (1991) clearly stated that the value appraisement on the loss is twice of the gain. People detest any form of loss and try to avoid them from happening. The prospect theory is an important theory in behavioral finance research, but it also has limitations. For example, when measuring the utility of people, researchers assume that the former utility in the past is the benchmark. People only care about the profit and loss, rarely concern about the uncertainty of the future and the effect of emotion and information on the behavioral decisions of respondents.

Research from the perspective of regret evading indicated that changes in the status quo may lead to greater sense of regret than maintaining the status quo (Kahneman, 2003; Gilovich and Medvec, 1994; Bomnger et al, 1994). It was found that respondents preferred to those decision-making which can minimize their expected sense of regret (Kahneman and Miller, 1986; Loomes and Sugden, 1982; Loomes,1988; Roese and Olson, 1995). According to whether or not people take action, Gleicher et al. (1990) divided regret into two categories, one derives from negative results with actions; the other derives from negative results with no action. Bomnger et al. (1994) considered that the regret sense comes from the former is more strong and durable than the latter for the same degree of negative results. Inman and Zeelenberg (2002), Ritov and Baron (1995), Johnson et al. (1993) found out that respondents always pay attention to those regret senses which derive from failure of their missions, but do not pay too much attention to ones result from negligence. Gilovich and Medvec (1994) showed that the regret sense which came from the results of changing the status quo was stronger than not changing the status quo; respondents were more compunctious with the negative outcomes which came from their action in the short time, but in long period they were more compunctious for the negative outcomes that they did not take the action. ${ }^{2}$ Thaler and Shefrin (1981) believed that besides the actual loss, regret also includes respondents' feeling of response for loss, so regret is more painful than actual loss. In China, Lai and Shi (2006) studied the relationship between regret responses on behavior of respondents and risk preference. Shi, Wang and Peng (2004) researched the behavior of respondents in symbolic situation and beneficial situation and whether the regret degree was different in the two situations. They found in symbolic situation respondents prefer to take action while in beneficial situation, respondents tend to take no action.

\footnotetext{
${ }^{2}$ Gilovich and Medvec collected 77 respondents' long-term regrets. Among all the 213 regrets (an average of 2.77 regrets for one person), 63 percents was regret for not action and only 37 percents were regret for taking actions (10 regrets were exclude for they can not be classified according to above standard).
} 
There are also other perspectives of research on status quo bias in the evaluation phase, such as the fuzzy offensive perspective (Tversky and Kahneman, 1974; Gilboa and Schmeidler, 1995). The research indicated investors prefer uncertainty gain to certainty gain and they prefer certainty loss to uncertainty loss; Researchers who investigate the status quo from perspective of experience (Burmeister and Schade, 2007; Kahneman et al., 1991) thought respondents prefer the status quo because of the impact of past experiences, and experiences have unilateral impact on status quo bias, which can increase respondents' sensitivity of status quo bias.

Existing studies have found that status quo bias is common. Studies on investors' status quo bias in the evaluation phase could only partly explain the source and the degree of status quo bias except the deep-seated reasons derived from information obtained phase and information edited phase. In these two phases, framing effect, investor emotion and information structure are the three typical sources of bias. Some existing studies on framing effect are as follows. Moxey et al. (2002) researched the impact of framing effect on decision-making of doctors. Reyna and Ellis (1994) studied the framing effect in the risk decision-making of children by using the "Asian disease problems" and the results showed that the framing effect can influence decision of older children significantly, while in contrast, this effect is not significant on younger children. Chinese scholars Wang and Liang found that the dynamic characteristics of framing effect were impacted by the nature, content and scene of the mission (1995). He, Liang and Liu (2002) found that the framing effect does exist in some risk scenarios when studying the risk preference prediction, and under the frames of profit and loss, the recognition of gender, the framework of task and the instant emotion have affected the risk preference prediction of respondents simultaneously. As a result, different frames result in different levels of status quo bias. We could make use of frames to decrease the level of investors' status quo bias. Based on the above analysis of influence of framing effect on investors' status quo bias, we propose the first hypothesis.

H1 Framing effect has a significant effect on investors' status quo bias, and investors' status quo bias is higher in price differential frame than in the ratio frame of the investable portfolio.

At present, when analyzing investor emotion, researchers often combine it with the prospect theory. In the past decade, studies on emotion have found more characteristics of emotion reaction, which prove that emotion is destructive to rational thinking and adaptive behavior is not comprehensive (Boysen, Bertson and Mukobi, 2001; Cacioppo and Gardner,1999). People have recognized that 
emotion also plays an important role in practice (Cacioppo and Gardner, 1999). Emotion also influences the decision of investors significantly. Status quo bias, as one of external expressions of irrationality of investment behaviors, is affected by emotion too. Schwarz and Clore (2003) found positive emotion can lead to more successful decisions. In Fishbach and Trope (2005), it was found that positive emotions could increase the wishes of the transaction and reduce the price gap between buyers and sellers, but the negative emotions had the opposite effect. In other words, positive emotion could reduce the attention that investors paid on negative emotion, strengthen the will of exchange, and reduce the gap of prices; while negative emotion improves the attention on bad emotion, which brings an opposite effect. Based on the above analysis of influence of emotion on investors' status quo bias, we propose the second hypothesis.

H2 Emotion has a significant effect on investors' status quo bias, and positive emotion would strengthen the investors' will of exchange, reduce the level of investors' status quo bias, while the negative emotion has the opposite effect.

Research in the effect of information structure on investors' status quo bias is also reviewed as follows. Ryan and Bate (2001) found respondents prefer the status quo mainly due to the relatively little information they have when changing their options. By exploring empirical studies, DuPont and Lee (2002) found asymmetric information contribute to inconsistent of WTA and WTP ${ }^{3}$ prices. Status quo bias could decrease the degree of fuzzy averse of investors. The stronger motivation of fuzzy averse, the greater degree of status quo bias is. These studies mainly focus on the existence of framing effect, investor emotion and information structure, as well as influence factors of these three aspects from the psychological perspective. However, researchers rarely combine these three aspects together and analyze the deep-seated reasons for investors' status quo bias in the information obtaining and editing phases. Based on the theories mentioned above, we study influence of information structure on the investors' status quo bias, and propose the third hypothesis.

H3 Information structure has significant effect on investors' status quo bias, and the level of status quo bias in self-status assignment group is higher than in external-status assignment group.

\footnotetext{
${ }^{3}$ WTA is the price that respondents are willing to accept when selling objects. WTP is the price that respondents are willing to pay when buying objects.
} 


\section{Experimental design and procedures}

\subsection{Experimental design}

We mainly design a framing effect and investors' status quo bias experiment by using different expressions of stock returns. Stock returns can be expressed by bid and offer price differential and by the return rate. Facing these two expressions, the same respondents can have different feelings. Therefore, this paper assumes that if using price differential to express the stock returns, respondents will have a higher level of status quo bias. In the experiment, there are altogether two questions and one respondent only answers one of them. In order to ensure the experiment quality, respondents are informed that there are non-standard answers to all the questions and they can answer the question in accordance with their own tendency. In order to avoid any psychological pressure to the respondents, all the experiments are anonymous. The experimenter required respondents to rank the four options and the favorite option will be ranked first, then the second and the third, the fourth is weakest. The main purpose of the design is to completely induce respondents' true preferences. Specific experimental frameworks are showed in Table 1.

Emotion has very important influence on investors' decision. Positive emotion can increase the wishes of transaction, reduce the price gap between buyers and sellers and reduce the level of status quo bias of respondents. In contrast, negative emotion has the opposite effect. In the experiment of investor emotion and status quo bias, we divide 60 respondents into three groups, positive emotion group, negative emotion group and neutral emotion group. And in each group, there are 20 respondents who are divided into two types of A and B. Specific experimental frameworks are showed in Table 1.

Status quo bias can reduce the ambiguity elusion degree of respondents. The stronger the motivation of ambiguity elusion, the higher the level of status quo bias. If respondents are endowed with no initial option, they prefer the game with determined probability. The degree of ambiguity elusion is different between respondents with initial ambiguous option and respondents with no option. Respondents with initial ambiguous option prefer to choose this ambiguous option. The status quo bias level of respondents in self-status assignment group is higher than the level of respondents in external-status assignment group. In this paper, we study the status quo bias level of respondents under different information structure condition, which mainly refers to the experimental design of Ellsberg who measured the status quo bias level with the rate between the number of changing options and the number of maintaining the options. Specific experimental frameworks are showed in Table 1. 


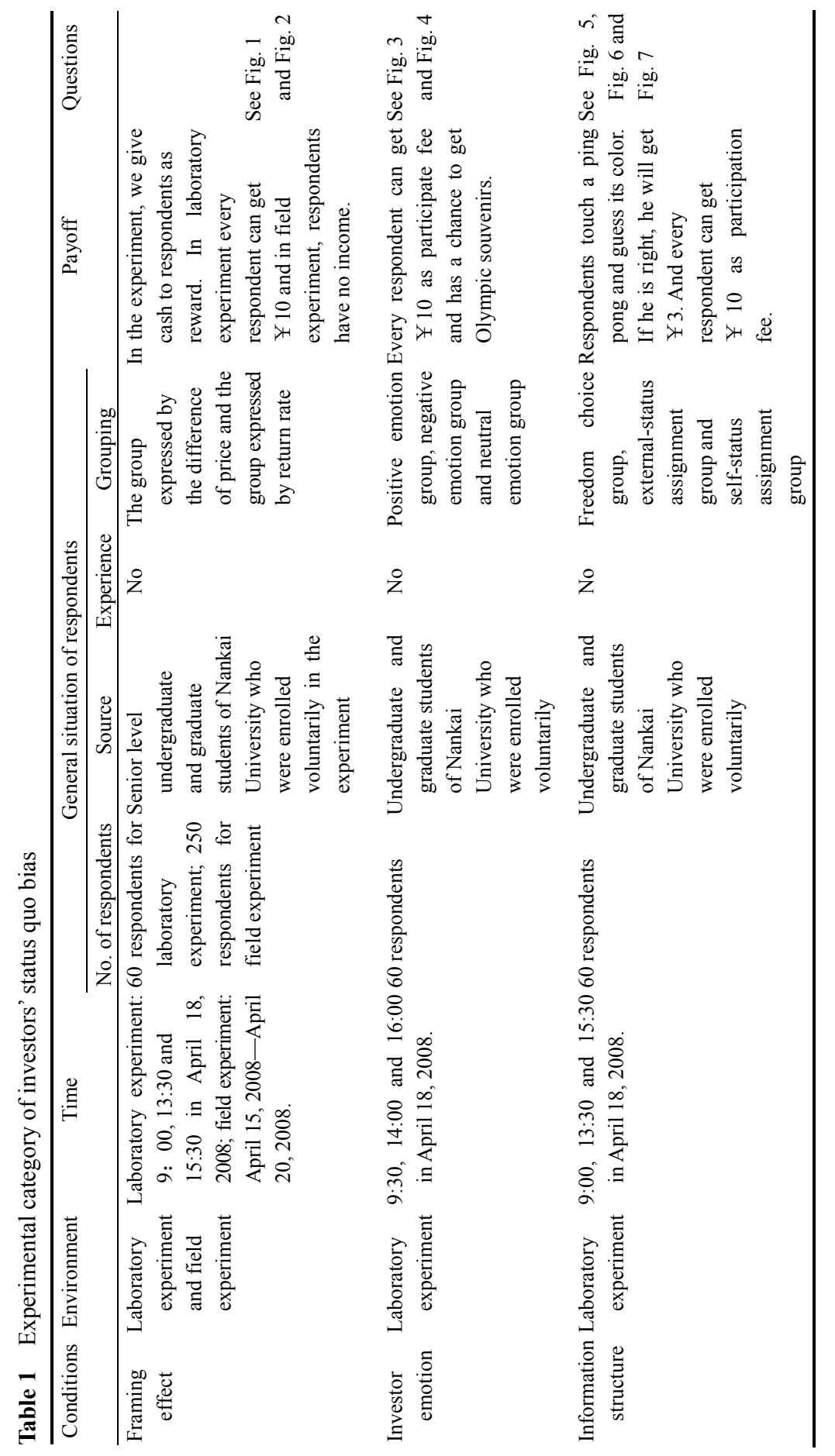




\subsection{Experimental procedures}

(1) The experimental process of framing effect and investors' status quo bias experiment. It consists of a laboratory experiment and a field experiment. The laboratory experiment was carried in Selten laboratory of Nankai University (so were the other two experiments).

First of all, respondents were given three minutes to understand the experimental introduction. Next, the experimenter read the experimental introduction and answered questions that the respondents might ask. The purpose was clarifying the experimental process instead of providing new information, especially not discussing the experimental aims or the expected results so as to ensure the respondents only know the public information. Then, respondents filled out the questionnaire as showed in Fig. 1 and Fig. 2. At the end of the experiment, the experimenter paid the respondents in cash as reward privately, took the record cards back, and interviewed some respondents based on the experimental results. Field experiments were carried out in students' dorms, who were selected randomly, and the process was mostly the same as in the laboratory.

Decision 1: Assuming that you were an investor in the stock market, you used all your money to buy stocks:

When the price of stock A was $¥ 18$ per share, you bought 100 shares and now the price is $¥ 21$, your profit is $¥ 300$; when the price of stock B was $¥ 17$ per share, you bought 200 shares and now the price is $¥ 15.5$, your loss is $¥ 300$. What will you do now?
A. Sell stock A and hold stock B
B. Hold all the stocks
C. Sell stock B and hold stock A
D. Sell all the stocks

Please rank above options in accordance with the strength of your wishes (from strong to weak).

Fig. 1 Record card of the price differential expressing group

Decision 2: Assuming that you were an investor in the stock market, you used all your money to buy stocks:

When the price of stock A was $¥ 18$ per share, you bought 100 shares and now your profit rate is $16 \%$; when the price of stock B was $¥ 17$ per share, you bought 200 shares and now your loss rate is $9 \%$. What will you do now?
A. Sell stock A and hold stock B
B. Hold all the stocks
C. Sell stock B and hold stock A
D. Sell all the stocks

Please rank above options in accordance with the strength of your wishes (from strong to weak).

Fig. 2 Record card of the return rate expressing group

(2) The experimental process of emotion and investors' status quo bias 
experiment. This experiment was carried out after the framing effect experiment. At first, respondents were required to watch a short film as necessary rests. Then, the experimenter announced that there were 10 presents for them as souvenirs for taking part in the experiment. After that, respondents played the finger-guessing game between each pair, and the winner of A type got a souvenir, a Crystal Olympic Fuwa. Then, the experimenters allowed the respondents to pass it from one to another to see the souvenir clearly. Finally, the experimenter distributed type A and type B record cards to the respondents (the whole process lasted less than 120 seconds). (See Fig. 3 and Fig. 4).

Your number:

Welcome to take part in the experiment and congratulations on your souvenir! Now you have the opportunity to sell the souvenir to the experimenter, please fill in the price you are willing to accept. ( $¥)$.

Fig. 3 Record card of type A respondents

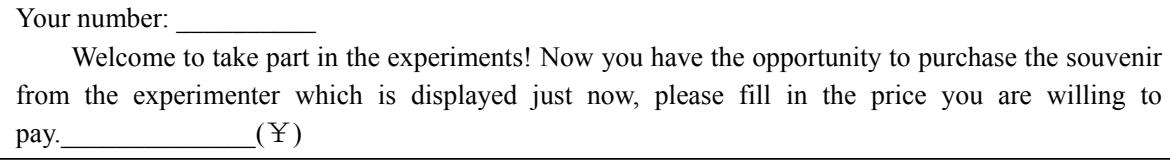

Fig. 4 Record card of type B respondents

After respondents finished the record cards, the experimenter collected them. Finally experimenter paid out the participation fee and interviewed some respondents. Specific organizational processes of the three experimental groups were as follows:

1) Positive emotion group. Played the short film Mr. Bean for 8 minutes. After the short film, the experimenter announced that every type A respondent could get an Olympic Games souvenir and the respondents had the opportunity to sell the souvenir to the experimenter. And type B respondents could purchase the souvenir from the experimenter at a certain price. Then experimenter allowed the respondents to pass it on from one to another to see the souvenir clearly and in the process respondents were not allowed to talk with each other. Five minutes later, type A respondents wrote down the price they were willing to accept on the experimental records and type $\mathrm{B}$ respondents wrote down the price they were willing to pay on the experimental records too. Finally, the experimenter collected all cards and make sure there was no mistake.

2) Negative emotion group. The process in the negative emotion group experiment was similar to the positive emotion group experiment, but we played a sad short film Kiss in this experiment (9 minutes). 
3) Neutral emotion group. The process in neutral emotion group experiment was similar to the above two experiments except that respondents in this group did not see the film.

(3) The experimental process of information structure and investors' status quo bias experiment. Respondents knew that there were two bags of ping-pong balls, which both contained 100 balls and that bag A contained 50 yellow and 50 white balls, but they did not know the specific number of yellow balls and white balls in bag B. This experiment divided respondents into three groups as free choice group, external-status assignment group and self-status assignment group. Each group had 20 respondents. Respondents touched a ping-pong ball and guessed its color. If he was right, he would earn $¥ 3$. In addition, every respondent could get $¥ 10$ as participation fee.

1) Freedom choice group. Experimenter read the experimental instruction after all respondents had arrived. Making sure that all respondents have understood the experimental process fully, the experimenter distributed experimental record cards. The record card was showed in Fig. 5. Then respondents chose the game based on bag A or bag B and completed the record cards. After that, respondents went to the bag in front of an assistant, touched a ball from the bag and guessed its color. At the same time, the experimenter collected the experimental record cards back and recorded the income of respondents. After all respondents had taken the balls, the experiment was over.

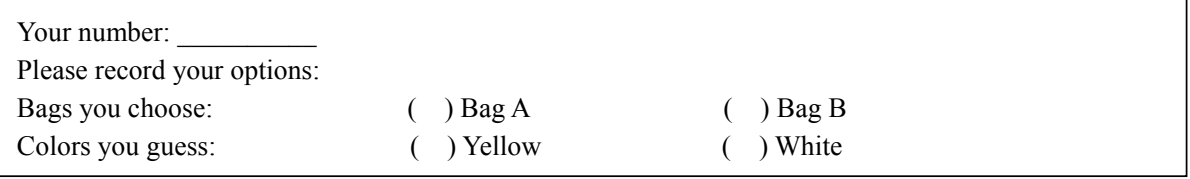

Fig. 5 Record card of respondents in freedom choice group

2) External-status assignment group. The experimenter read the experimental instruction after all respondents had arrived. After respondents understood the experimental process fully, they drew lots to decide the game based on bag A or B. Respondent whose number was odd is assigned Bag A Game (touch a ball in bag $\mathrm{A}$ and guess color) and respondent with an even number was assigned Bag $\mathrm{B}$ Game (to touch a ball in bag B and guess color) and at the same time they filled out the experimental record cards. The record card was shown as in Fig. 6. After 180 seconds, respondents had the opportunity to change Bag A Game or Bag B Game by marking the changed options on the record cards (Respondents who changed the options should mark on the blank space of the record cards). Then respondents could touch balls from the bags that they re-selected in accordance with their number. Finally, the experimenter collected the record cards and 
recorded the income of respondents. After all respondents had taken the balls, the experiment was completed.

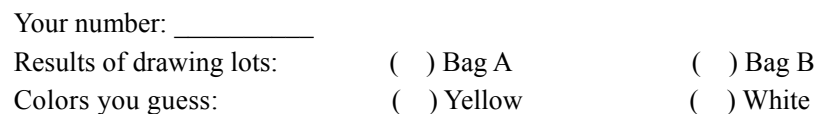

Fig. 6 Record card of respondents in external-status assignment group

3) Self-status assignment group. The experimenter read the experimental instruction after all respondents had arrived. After respondents understood the experimental process fully, they chose bag A Game or bag B Game in 60 seconds (We consider this step increased the feeling of ownership for respondents). Experimental assistants distributed the record card, which is shown in Fig. 7. After 180 seconds, respondents had the opportunity to change the results of their initial choice. Respondents could take balls from the bags that they re-selected according to their serial number after they marked the changed options on the record cards (Respondents who changed the options should mark on the blank space at the top of the record cards). Finally, the experimenter collected the record cards and recorded the income of respondents. After all respondents had taken the balls, the experiment was over.

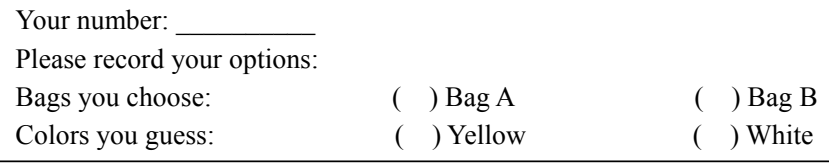

Fig. 7 Record card of respondents in self-status assignment group

\section{Analysis of experimental results}

4.1 Results analysis of framing effect and investors' status quo bias experiment

(1) Descriptive statistical analysis. Among all questionnaires, for decision-making type 1,107 copies were valid. There were 32 respondents choosing option A, 51 choose option B, 15 choose option C, and 9 choose option D. Among all questionnaires, for decision-making type 2,112 copies were valid. There were 44 respondents choose option A, 35 respondents choose option B, 22 respondents choosing option $\mathrm{C}$ and 11 respondents choosing option $\mathrm{D}$. We can see that in the experimental frame of price differential, respondents believed that holding all the stocks was the optimal choice, but in experimental frame of return rate, selling 
stock A and hold stock B was considered to be the best choice. We define option $\mathrm{B}$ as 1 and non-option B as 0, Decision-making Group One as 1 and Decision-making Group Two as 2 in order to analyze the proportion of option B in the total number through Crosstabs. Statistical results are showed in Table 2.

Table 2 Results of crosstabs of framing effect and investors' status quo bias experiment

\begin{tabular}{|c|c|c|c|c|}
\hline \multirow[t]{2}{*}{ Decision-making types } & \multirow[t]{2}{*}{ Items } & \multicolumn{2}{|c|}{ Option B } & \multirow[t]{2}{*}{ Total } \\
\hline & & 0 & 1 & \\
\hline \multirow[t]{8}{*}{1} & No. & 56 & 51 & 107 \\
\hline & Expected No. & 65.0 & 42.0 & 107.0 \\
\hline & $\%$ within decision-making types & $52.3 \%$ & $47.7 \%$ & $100.0 \%$ \\
\hline & $\%$ within option $\mathrm{B}$ & $42.1 \%$ & $59.3 \%$ & $48.9 \%$ \\
\hline & $\%$ of Total & $25.6 \%$ & $23.3 \%$ & $48.9 \%$ \\
\hline & Residual & -9.0 & 9.0 & \\
\hline & Std. residual & -1.1 & 1.4 & \\
\hline & Adjusted residual & -2.5 & 2.5 & \\
\hline \multirow[t]{7}{*}{2} & No. & 77 & 35 & 112 \\
\hline & Expected No. & 68.0 & 44.0 & 112.0 \\
\hline & $\%$ within decision-making types & $68.8 \%$ & $31.3 \%$ & $100.0 \%$ \\
\hline & $\%$ of Total & $35.2 \%$ & $16.0 \%$ & $51.1 \%$ \\
\hline & Residual & 9.0 & -9.0 & \\
\hline & Std. residual & 1.1 & -1.4 & \\
\hline & Adjusted residual & 2.5 & -2.5 & \\
\hline \multirow[t]{4}{*}{ Total } & No. & 133 & 86 & 219 \\
\hline & Expected No. & 133.0 & 86.0 & 219.0 \\
\hline & $\%$ within decision-making types & $60.7 \%$ & $39.3 \%$ & $100.0 \%$ \\
\hline & $\%$ of total & $60.7 \%$ & $39.3 \%$ & $100.0 \%$ \\
\hline
\end{tabular}

Source: Data is collected by the authors based on the statistical output of SPSS 16.0.

(2) Significant test analysis. Pearson value is 6.182 , accompanied probability is 0.013 and it is less than significant level of 0.05 in Table 3, which means the proportion of option B in the experimental frame of price differential is higher than that in experimental frame of return rate significantly. Therefore, we can conclude that different expressions impact status quo bias significantly. Compared to expression of the return rate, the status quo bias degree of respondents in the experimental frame of price differential is higher. This result demonstrates framing effect has a significant impact on investors' status quo bias. 
Table 3 Chi-square statistics results of framing effect and investors' status quo bias experiment

\begin{tabular}{|c|c|c|c|c|c|}
\hline & Value & d.f. & $\begin{array}{l}\text { Asymp. sig. } \\
\text { (2-sided) }\end{array}$ & $\begin{array}{l}\text { Exact sig. } \\
\text { (2-sided) }\end{array}$ & $\begin{array}{l}\text { Exact sig. } \\
\text { (1-sided) }\end{array}$ \\
\hline Pearson Chi-Square & $6.182^{\mathrm{a}}$ & 1 & 0.013 & & \\
\hline Continuity correction ${ }^{\mathrm{b}}$ & 5.513 & 1 & 0.019 & & \\
\hline Likelihood ratio & 6.210 & 1 & 0.013 & & \\
\hline Fisher's exact test & & & & 0.018 & 0.009 \\
\hline $\begin{array}{l}\text { Linear-by-linear } \\
\text { association }\end{array}$ & 6.153 & 1 & 0.013 & & \\
\hline No. of valid cases & 219 & & & & \\
\hline
\end{tabular}

Note: Data is collected by the authors based on the statistical output of SPSS 16.0.

${ }^{a} 0$ cells $(0 \%)$ have expected count less than 5 . The minimum expected count is 42.02 .

${ }^{\mathrm{b}}$ Computed only for a $2 \times 2$ table.

In this experiment, the expression of profit and loss is easier to understand in the experimental frame of price differential than in the experimental frame of return rate. Therefore, respondents in the experimental frame of price differential can know their profit and loss very directly. Without taking into account the time value of money, respondents are aware that they have neither loss nor profit, so they tend to maintain the status quo, continuing to hold all stocks. Because the profit and loss of respondents is expressed by rate in experimental frame of return rate, its accessibility is weak. Therefore, it is difficult for respondents to understand their situation of profit and loss intuitively. In addition, with the influence of disposition effect, respondents tend to sell profit stocks to lock in profitable revenue and continue to hold the loss stock which can be observed in experimental frame of return rate (There are 44 respondents who thought option B-"Sell stock A and hold stock B"-is the optimal choice, which accounted for about $40 \%$ ).

\subsection{Results analysis of emotion and investors' status quo bias experiment}

(1) Descriptive statistical analysis. Descriptive statistics results of WTA values and WTP values under the three states of emotion are shown in Table 4 and Table 5. The WTA/WTP value is about 1.64 in positive emotion group, 2.35 in negative group and 2.15 in neutral group. From above statistics, we can see that the level of investors' status quo bias is lowest under positive emotion and is highest under negative emotion. 
Table 4 Descriptive statistics results of WTA price under the three states of emotion

\begin{tabular}{lcccccc}
\hline \multirow{2}{*}{ Types } & \multirow{2}{*}{ Amount } & \multirow{2}{*}{ Mean $(¥)$} & \multicolumn{2}{c}{$95 \%$ confidence interval of the mean } & \multirow{2}{*}{ Min } & \multirow{2}{*}{ Max } \\
\cline { 5 - 6 } & & & Lower boundary & Upper boundary & & \\
\hline Positive & 10 & 8.85 & 5.23 & 12.47 & 1 & 15 \\
Negative & 10 & 8.00 & 2.11 & 13.89 & 3 & 30 \\
Neutral & 10 & 8.50 & 4.15 & 12.85 & 2 & 30 \\
Total & 30 & 8.45 & 6.36 & 11.87 & 1 & 30 \\
\hline
\end{tabular}

Table 5 Descriptive statistics results of WTP price under the three states of emotion

\begin{tabular}{lcccccr}
\hline \multirow{2}{*}{ Types } & \multirow{2}{*}{ Amount } & \multirow{2}{*}{ Mean $(¥)$} & \multicolumn{2}{c}{$95 \%$ confidence interval of the mean } & \multirow{2}{*}{ Min } & \multirow{2}{*}{ Max } \\
\cline { 4 - 6 } & & & Lower boundary & Upper boundary & & \\
\hline Positive & 10 & 5.40 & 3.29 & 7.51 & 1 & 10 \\
Negative & 10 & 3.40 & 1.16 & 5.64 & 0 & 10 \\
Neutral & 10 & 3.95 & 2.20 & 5.00 & 0 & 6 \\
Total & 30 & 4.25 & 3.09 & 5.17 & 0 & 10 \\
\hline
\end{tabular}

(2) Significant tests. Table 6 presents the variance homogeneity test results of WTA prices and WTP prices which are separated in the three experiments of emotions. It is observed that the significant level of four indicators are all less than 0.05 . Therefore, we conclude there are significant differences between the two prices. The WTA prices are higher than WTP prices significantly and WTA/WTP value is about 2.05 .

Table 6 Variance homogeneity test results of WTA and WTP

\begin{tabular}{lcccc}
\hline & Levene statistic & $d_{\text {.f. }} ._{1}$ & $d_{.} f_{2}$ & Sig. \\
\hline Based on mean & 9.120 & 1 & 58 & 0.004 \\
Based on median & 7.797 & 1 & 58 & 0.007 \\
Based on median and with adjusted $d . f$. & 7.797 & 1 & 37.532 & 0.008 \\
Based on trimmed mean & 8.163 & 1 & 58 & 0.006 \\
\hline
\end{tabular}

In order to study the fluctuation range of WTA and WTP prices, Fig. 8 and Fig. 9 present the normal probability graphs of WTA and WTP price variable. As shown in Fig. 8, there are some points which deviate from the normal distributing slash seriously in the normal probability graph of WTA price variable and the prices respondents are willing to accept scatter. From Fig. 9 we can see most points are close to the normal distributing slash in normal probability graph of WTP price variable and the prices respondents are willing to pay relatively concentrate. We hence can draw a conclusion that WTA prices are higher than WTP prices significantly and the fluctuation range of WTA prices is larger than WTP prices. 


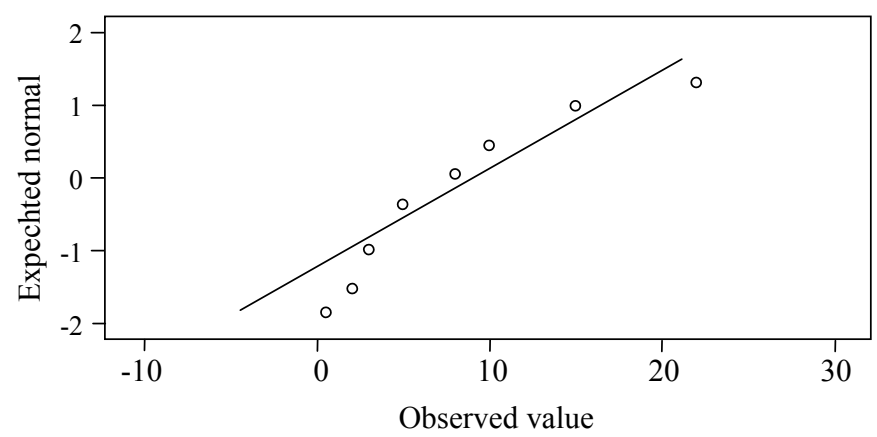

Fig. 8 Normal probability graph of WTA price variable Note: The graph is obtained using SPSS 16.0.

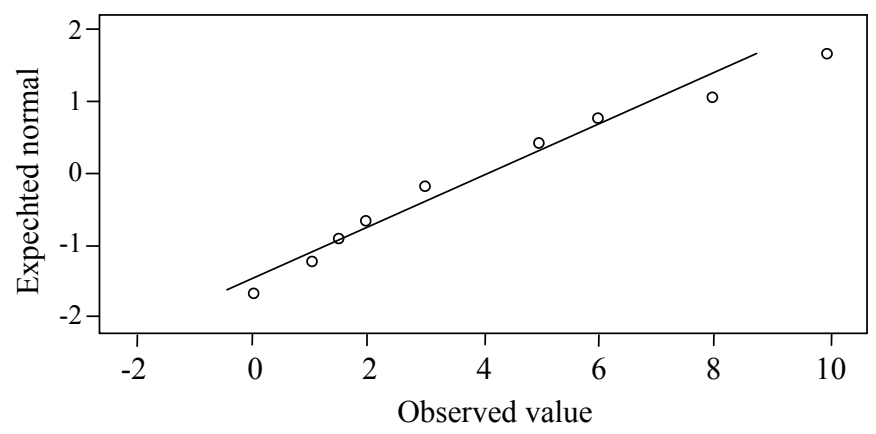

Fig. 9 Normal probability graph of WTP price variable

Note: The graph is obtained using SPSS 16.0.

4.3 Results analysis of information structure and investors' status quo bias experiment

(1) Descriptive statistical analysis. Actually, freedom choice group, external-status assignment group and self-status assignment group are three different information structures. Experimental results of the three groups are shown in Table 7. From Table 7, we can see there are only 5 respondents who choose vague option of bag B in freedom choice group which has 20 respondents. This indicates that the majority of respondents have the tendency to elude vague options when they face the vague options. In addition, the rate of choosing the options of certain probability is five times as the options of vague probability. In the experiment of external-status assignment group, the ratio of reserving options is three times as changing options. Moreover among the ten respondents who have been endowed with vague option, nine retain the vague bag. These results prove the previous assumptions. 
Table 7 Statistical results of status quo bias experiments under different information structure

\begin{tabular}{|c|c|c|c|c|c|}
\hline \multirow{2}{*}{$\begin{array}{l}\text { Serial number } \\
\text { of respondent }\end{array}$} & \multirow{2}{*}{$\begin{array}{l}\text { Freedom choice } \\
\text { group }\end{array}$} & \multicolumn{2}{|c|}{ External-status assignment group } & \multicolumn{2}{|c|}{ Self-status assignment group } \\
\hline & & Endowed option & Final option & Endowed option & Final option \\
\hline 1 & A & A & A & A & A \\
\hline 2 & A & A & B & B & A \\
\hline 3 & A & A & A & B & A \\
\hline 4 & A & A & B & B & $\mathrm{B}$ \\
\hline 5 & B & $\mathrm{B}$ & $\mathrm{A}$ & $\mathrm{A}$ & $\mathrm{A}$ \\
\hline 6 & A & A & B & B & A \\
\hline 7 & A & A & A & B & A \\
\hline 8 & A & A & B & B & A \\
\hline 9 & A & A & A & A & B \\
\hline 10 & B & B & B & B & $\mathrm{B}$ \\
\hline 11 & B & B & A & A & A \\
\hline 12 & A & A & B & B & A \\
\hline 13 & A & A & A & B & A \\
\hline 14 & A & A & B & A & A \\
\hline 15 & B & B & A & A & A \\
\hline 16 & B & B & B & B & A \\
\hline 17 & A & A & A & B & A \\
\hline 18 & A & A & B & B & B \\
\hline 19 & A & A & A & A & B \\
\hline 20 & A & A & B & B & B \\
\hline
\end{tabular}

Surprisingly, among the ten respondents who were endowed with the option A initially, four changed their options to the vague option B. We think there are two main reasons contribute to this change: one is that respondents do not trust the experimenter; the other is the study among respondents. In the experiment, the No.7 respondent earned $¥ 3$ after he had changed his option from A to B, which may lead to similar actions of other respondents. Actually, the interviews after the experiment confirm this conjecture. In addition, among 20 respondents in self-status assignment group, only 4 chose the vague option of bag B and this proves the above assumption again. All of the 4 respondents who initially chose vague option retain the vague option of bag $B$. However, among 16 respondents who initially chose certain options of bag A, 2 changed their options from certain A to vague $B$.

(2) Experimental results. From the above analysis, we can find the rate of 
maintaining the status quo is $75 \%$ in external-status assignment group, $90 \%$ in self-status assignment group, which means the status quo bias level of respondents in external-status assignment group is lower than self-status assignment group. Obviously, the experimental results are consistent with previous assumptions. In other words, rights of choosing options freely can strengthen respondents' sense of ownership and then improve the status quo bias of respondents. This paper analyzes whether the rate of choosing vague options is significantly different between respondents in freedom choice group and respondents in external-status assignment group by using crosstabs analysis. We define option $\mathrm{A}$ as 0 and $\mathrm{B}$ as 1 . Table 8 presents the experimental results which show that the chi-square value is 6.465 and accompanied probability is 0.011 (smaller than the significant level of 0.05). Therefore, we conclude that the degree of eluding vague options is significantly different between freedom choice group and external-status assignment group. And we believe the status quo bias can reduce the degree of eluding vague, which also proves the existence of investors' status quo bias and its impact on the decision-making of respondents in one aspect.

Table 8 Statistical results of freedom choice and external-status assignment group experiment

\begin{tabular}{|c|c|c|c|c|}
\hline & Value $d . f$. & Asymp. sig. (2-sided) & Exact sig. (2-sided) & Exact sig. (1-sided) \\
\hline Pearson Chi-Square & $6.465 \quad 1$ & 0.011 & & \\
\hline Continuity correction & $4.949 \quad 1$ & 0.026 & & \\
\hline Likelihood ratio & 6.6601 & 0.010 & & \\
\hline Fisher's exact test & & & 0.025 & 0.012 \\
\hline No. of valid cases & 40 & & & \\
\hline
\end{tabular}

\subsection{Regression analysis of experimental variables and investors' status quo bias}

Based on the above two experiments, we proceed to use the logistic regression to analyze the relationship between gender, education, WTA, WTP and the status quo bias comprehensively. Because the same group of respondents participates in information structure experiment and investor emotion experiment, we mainly investigate on the neutral emotion-external-status assignment group. The definitions of gender variables and educational variables are as follows. 1 is male and 0 is female; 1 is undergraduate student and 0 is master. In addition, we define dependent variables (the status quo bias variables): 1 as changing the option and 0 as maintaining the option. Table 9 presents statistical results. It shows the accuracy is $85.7 \%$ for $y=0,33.3 \%$ for $y=1$ and $70 \%$ for all cases. 
Table 9 Fitting effect of iterative results for neutral emotion-WTA-external status assignment

\begin{tabular}{|c|c|c|c|c|}
\hline & & \multicolumn{3}{|c|}{ Predicted } \\
\hline \multicolumn{2}{|c|}{ Observed } & \multicolumn{2}{|c|}{$y$} & \multirow{2}{*}{$\begin{array}{l}\text { Percentage of } \\
\text { being correct }\end{array}$} \\
\hline & & 0 & 1 & \\
\hline \multirow[b]{2}{*}{$y$} & 0 & 6 & 1 & 85.7 \\
\hline & 1 & 2 & 1 & 33.3 \\
\hline \multicolumn{2}{|c|}{ Overall percentage } & & & 70.0 \\
\hline
\end{tabular}

Note: Data is obtained using SPSS 16.0.

Table 10 presents the coefficients of all variables and the corresponding Wald statistical values and their accompanied probability values. As shown, the Wald statistical value of $X_{3}$ is the largest and its accompanied probability is the smallest, that means this variable is very important in the model. The coefficient of WTA is negative, which demonstrates that the lower of asking price, the easier to change the status quo. The coefficient of WTA is also negative. In other words, the status quo bias degree of female is higher than male. Besides, the coefficient of education is positive, that is to say, the higher of education, the lower of the status quo bias degree.

Table 10 Regression results of neutral emotion group-WTA-external status assignment

\begin{tabular}{lccccccc}
\hline & & & & & \multicolumn{3}{c}{$95.0 \%$ confidence } \\
& Coefficients & S.E. & Wald & $d . f$. & Sig. & \multicolumn{2}{c}{ interval for EXP (B) } \\
\cline { 6 - 8 } & & & & & & Lower & Upper \\
\hline$X_{1}$ (Gender) & -1.097 & 2.140 & 0.263 & 1 & 0.608 & 0.005 & 22.126 \\
$X_{2}$ (Education) & 0.945 & 2.089 & 0.205 & 1 & 0.651 & 0.043 & 154.319 \\
$X_{3}$ (Asking Price) & -0.173 & 0.317 & 1.738 & 1 & 0.390 & 0.409 & 1.418 \\
Constants & 0.978 & 2.081 & 0.221 & 1 & 0.638 & & \\
\hline
\end{tabular}

Source: Data obtained using SPSS 16.0.

Table 11 and Table 12 present the results of neutral emotion-WTPexternal-status assignment group. Table 11 shows the fitting effect of iterative results. The accuracy is $87.5 \%$ for $y=0,50 \%$ for $y=1$ and $80 \%$ for all cases. Table 12 shows the coefficients of all variables and the corresponding Wald statistical values and their accompanied probability values. The coefficient of WTP is negative, which means that the higher of the bid, the easier to change the status quo. The coefficient of gender is also negative and this shows that the status quo bias degree of female is higher than male. The coefficient of education is positive. In other words, the higher of education, the lower of the status quo bias degree. 
Table 11 Fitting effect of iterative results for neutral emotion-WTP-external status assignment

\begin{tabular}{|c|c|c|c|c|}
\hline \multirow{3}{*}{\multicolumn{2}{|c|}{ Observed }} & \multicolumn{3}{|c|}{ Predicted } \\
\hline & & \multicolumn{2}{|c|}{$y$} & \multirow{2}{*}{ Percentage correct } \\
\hline & & 0 & 1 & \\
\hline \multirow[b]{2}{*}{$y$} & 0 & 7 & 1 & 87.5 \\
\hline & 1 & 1 & 1 & 50.0 \\
\hline \multicolumn{2}{|c|}{ Overall percentage } & & & 80.0 \\
\hline
\end{tabular}

Source: Data obtained using SPSS 16.0.

Table 12 Regression results of neutral emotion-WTP-external status assignment

\begin{tabular}{lccccc}
\hline & Coefficients & S.E. & Wald & d.f. & Sig. \\
\hline$X_{1}$ (Gender) & -1.112 & 1.103 & 0.275 & 1 & 0.612 \\
$X_{2}$ (Education) & -0.748 & 2.014 & 1.305 & 1 & 0.271 \\
$X_{3}$ (Bid) & 0.105 & 1.007 & 0.836 & 1 & 0.394 \\
Constants & 2.018 & 2.341 & 0.337 & 1 & 0.326 \\
\hline
\end{tabular}

Source: Data obtained using SPSS 16.0.

From the regression results of neutral emotion-WTA-external-status assignment group and neutral emotion-WTP-external-status assignment group, we can draw the following conclusions: the higher of the bid, the easier to change the status quo; the lower of offer, the easier to change the status quo; the degree of women's status quo bias is higher than men and the higher of education, the lower level of this status quo bias.

\section{Conclusion}

Investors' status quo bias mainly derives from the obtaining phase, the editing phase and the evaluation phase of information. Current studies mostly focus on the evaluation phase from the perspectives of the prospect theory, the regret evading and etc. However, the status quo biases in decision-making information obtaining phase and editing phase cause more deep-seated problems. Besides, framing effect, investor emotion and information structure are three typical problems in above two phases and they have important impact on investors' status quo bias. By exploring the principles and methods of behavioral economics and experimental economics, this paper designs three experiments so as to analyze framing effect, investor emotion and information structure influence on investors' status quo bias in different experimental settings.

In the experiment of framing effect and investors' status quo bias, we focus on 
the investors' status quo bias level in the experimental frame of price gap and experimental frame of return rate. Results show that the investors' status quo bias level in the frame of profit and loss expressed by price gap is significantly higher than in the return rate frame.

In the experiment of investor emotion and status quo bias, we make use of the images of stories to induce respondents' positive emotion and negative emotions, together with the experimental group with no emotion induced as the benchmark to research their status quo bias level. Studies show that the value of WTA/WTP under positive emotion is 1.64 , which is the smallest, and the value under negative emotion is 2.35. These results demonstrate that WTA and WTP are different under positive emotion and negative emotion for the respondents of investors. The respondents have higher transaction willingness and lower status quo bias level under positive emotion and the respondents have lower transaction willingness and higher status quo bias level under negative emotion.

In the experiment of information structure and investors' status quo bias, we measure investors' status quo bias level respectively by setting up $2 \times 3$ experiments. We find out that in the basic experiment, respondents have the tendency to elude vague options and their choice of certain options is five times as uncertain options. The status quo bias level of respondents in external-status assignment group is lower than in self-status assignment group. In external-status assignment group, $75 \%$ respondents of investors maintain the status quo, while in self-status assignment group, the rate is $90 \%$.

This paper uses experimental methods to investigate the impact of above three factors on investors' status quo bias with Chinese respondents. Its conclusions may be significant to reduce status quo bias of Chinese investor and improve investors' veracity of decision. This study may also have reference meaning in making valid policy and increasing supervision for Chinese government departments. However, respondents' surroundings, for example, institution, culture and etc. may influence results of experiments. This requires us to consider the differences of institution and culture when designing experiments for future studies.

Acknowledgements This work is supported by the National Nature Science Foundation of China (No. 70672029 and 70532001), project of Key Research Institute of Humanities and Social Science in Universities (No. 05JJD630023), and Social Science 985 Project "Management and institution innovation of Corporate in China".

\section{References}

Bomnger D S, Gleicher F, Strathman A (1994). Counterfactual thinking: From what might 
have been to what may be. Journal of Personality and Social Psychology, 67(22): 297-307

Bourne G R (1993). Proximate costs and benefits of mate acquisition at leks of the frog Ololygon rubra. Animal Behaviour, 45(6): 1051-1059

Boysen S T, Bertson G G, Mukobi K L (2001). Size matters: Impact of item size and quantity on array of choice by a chimpanzee (Pan troglodytes). Journal of Comparative Psychology, 115(4): 106-110

Burmeister K, Schade C (2007). Are entrepreneurs' decisions more biased? An experimental investigation of the susceptibility to status quo bias. Journal of Business Venturing, 22(3): $340-362$

Cacioppo J T, Gardner W L (1999). Emotion. Annual Review of Psychology, 50(1): 191-214

Dupont D Y, Lee G S (2002). The endowment effect, status quo bias and loss aversion: Rational alternative explanation. The Journal of Risk and Uncertainty, 25(1): 87-101

Fishbach A, Trope Y (2005). The substitutability of external control and self-control. Journal of Experimental Social Psychology, 41(3): 256-270

Gilboa I, Schmeidler D (1995). Case-based decision theory. The Quarterly Journal of Economics, 110(3) : 5-39

Gilovich T, Medvec V H (1994). The temporal pattern to the experience of regret. Journal of Personality and Social Psychology, 67(33): 357-365

Gleicher F, Kost K A, Baker S M, Strathman A J, Richman S A, Sherman S J (1990). The role of counterfactual thinking in judgments of affect. Personality and Social Psychology Bulletin, 16(2) : 284-295

Inman J J, Zeelenberg M (2002). Regret in repeat purchase versus switching decisions: The attenuating role of decision justifiability. Journal of Consumer Research, 29(6): 116-128

Johnson E J, Hershey J, Meszaros J, Kunreuther H (1993). Framing, probability distortions, and insurance decisions. Journal of Risk and Uncertainty, 7(1): 35-51

Kahneaman D (2003). Maps of bounded rationality: Psychology for behavioral economics. American Economic Review, 93(5): 1449-1475

Kahneman D, Knetsch J L, Thaler R (1991). The endowment effect, loss Aversion and status quo bias. Journal of Economic Perspectives, 5(1):193-206

Kahneman D, Miller D T (1986). Norm theory: Comparing reality to its alternatives. Psychology Review, 93(2) : 136-153

Kahneaman D, Tversky A (1979). Prospect theory: An analysis of decision making under risk. Econometrica, 47(3): 63-91

Loomes G (1998). Further evidence of the impact of regret and disappointment in choice under uncertainty. Economica, 55(217):47-62

Loomes G, Sugden R (1982). Regret theory: An alternative theory of rational choice under uncertainty. The Economic Journal, 92(368): 805-824

Moxey A, Connell D O, Mcgettigan P, Henry D (2003). Describing treatment effects to patients-How they are expressed makes a difference? Journal of General Internal Medicine, 18(11): 948-959

Reyna V F, Ellis S C (1994). Fuzzy-trace theory and framing effects in children's risky decision making. Psychological Science, 5(5): 275-279

Ritov I, Baron J (1995). Outcome knowledge, regret, and omission bias. Organizational Behavior and Human Decision Processes, 64(2):119-127

Roese N J, Olson J M (1995). Outcome controllability and counterfactual thinking. Personality and Social Psychology Bulletin, 21(6): 620-628

Ryan M, Bate A (2001). Testing the assumptions of rationality, continuity and symmetry when applying discrete choice experiments in health care. Applied Economics Letters, 8(1): 59-63 
Samuelson W, Zeckhauser R (1988). Status quo bias in decision making. Journal of Risk and Uncertainty, 1(1): 7-59

Schwarz N, Clore G L (2003). Mood as information: 20 years later. Psychological Inquiry, 14(3):296-303

Thaler R H, Shefrin H M (1981). An economic theory of self-control. The Journal of Political Economy, 89(2): 392-406

Tversky A, Kahneman D (1974). Judgment under uncertainty: Heuristics and biases. Science, 185(9): 1124-1131

Tversky A, Kahneaman D (1991). Loss aversion in riskless choice: A Reference-dependent model. The Quarterly Journal of Economics, 106(4): 1039-1061

王重鸣, 梁立 (Wang Chongming, Liang Li) (2005). 风险决策中动态框架效应研究 (A study on dynamic framing effects in risky decision). 心理学报, (4): 394-400

何贵兵, 梁社红, 刘剑 (He Guibing, Liang Shehong, Liu Jian) (2002). 风险偏好预测中的性别差 异和框架效应 (Effects of gender stereotypes and task frames on risk preference predictions). 应用心理学, (4): 19-23

赖志刚, 时勘 (Lai Zhigang, Shi Kan) (2007). 后悔倾向、后悔反应与风险偏好的关系研究 (A study on the relationships among regret orientation, regret response and risk preference). 管 理评论, (3): 3-7

施俊琦, 王垒, 彭凯平 (Shi Junqi, Wang Lei, Peng Kaiping). 作为效应的象征性与利益性影响因 素: 后悔理论的经济心理学分析 (Symbolic and economic factors in action effect: An economic-psychological analysis of regret theory). 心理科学, (4): 1016-1018 